\title{
Educational Mixology: A Pedagogical Approach to Promoting Adoption of Technology to Support New Learning Models in Health Science Disciplines
}

\author{
Paige L. McDonald, Laurie B. Lyons, Howard O. Straker, Jacqueline S. Barnett, Karen S. Schlumpf, \\ Linda Cotton, and Mary A. Corcoran \\ The George Washington University \\ School of Medicine and Health Sciences
}

\begin{abstract}
For disciplines heavily reliant upon traditional classroom teaching, such as medicine and health sciences, incorporating new learning models may pose challenges for students and faculty. In an effort to innovate curricula, better align courses to required student learning outcomes, and address the call to redesign health professions education, Health Sciences Programs at The George Washington University (GW) embarked on two faculty-development initiatives to encourage adoption of online, blended, and technology-enhanced courses. This article describes the Review, Refresh, and Revise (R3) program, which relies on the evidenced-based Quality Matters Higher Education Rubric and resources from the Supported Media for Administration and Teaching (SMART) Lab to develop and promote a pedagogical approach to course redesign. It also presents preliminary data evaluating the programs in terms of faculty satisfaction, student satisfaction, learning outcomes, and learner engagement. Data analysis indicates faculty satisfaction with the R3 program and SMART Lab resources despite faculty concerns regarding the time commitment required by R3. It also indicated that both initiatives improved course quality, learning outcomes, and learner engagement. Analysis indicates student satisfaction with course revisions in online and technology-enhanced courses, although student satisfaction in the first fully blended course varied, particularly with regard to whether students found the use of technology engaging or essential to learning. Further research is required to understand student responses to blended learning in health sciences.
\end{abstract}

\section{Educational Mixology: A Pedagogical Approach to Promoting Adoption of Technology to Support New Learning Models in Health Science Disciplines}

Institutions of higher learning are currently grappling with the question of how to deliver rigorous learning experiences through flexible delivery platforms to meet the needs of an increasingly fast-paced and complex society. Access, affordability, program structure and duration pose barriers to participation in traditional higher education programs (Advisory Committee on Student Financial Assistance, 2012; Oreopoulos \& Petronijevic, 2013; Zarate \& Burciaga, 2010). As a result, institutions of higher learning are under increasing pressure to adopt "affordable, sustainable approaches” (Beckem \& Watkins, 2012, p. 61) that provide access to students who cannot meet the demands of traditional full-time programs. In response, many institutions have increasingly incorporated online courses and programs within their delivery models. In fact, in a study tracking online learning in the United States, Allen and Seaman (2014) 
found that the proportion of students taking online courses was at an "all-time high" in 2013 at 26\% (p. 4). Additionally, $90 \%$ of academic leaders surveyed reported that it is "likely" or "very likely" that "a majority of all higher education students will be taking at least one online course in five years' time” (p. 5). In terms of quality, $74 \%$ of academic leaders queried rated the learning outcomes of online education as "the same as or superior to those as in face-to-face instruction" (p. 4). Still, promotion of online learning (either fully online or blended courses) can prove challenging in traditional disciplines heavily reliant upon lecture-based and experiential learning, such as medicine and health sciences.

Complicating the potential "redesign" of higher education are questions regarding its purpose. A Pew Research poll of the public in 2011 found that 57\% of Americans say the U.S. higher education system does not provide a good value for the money (Taylor et al., 2011). Others question how institutions of higher education will respond to pressure from the marketplace to add "value" to a degree by ensuring "gainful employment" upon receipt (Staley \& Trinkle, 2011, p. 24). While institutions of higher learning have traditionally focused on imparting subject-oriented knowledge (information), many now question their increasing role in building student skills needed to survive in an ever-changing, knowledge-based economy, particularly development of higher level thinking skills that will enable continual adaptation and change. In response, some universities incorporate competency-based skills such as "critical thinking, writing and quantitative literacy" (Berrett, 2011, para. 6) during the first two years of an undergraduate curriculum. Questions regarding course and curriculum redesign also relate to structure and pedagogical approach; a Pew Internet study (Anderson, Boyles, \& Rainie, 2012) of tech experts' opinions on higher education reported an expected increase in adoption of new approaches to teaching, and adoption of new pedagogical approaches in conjunction with retention of traditional methods. It also reported an expected increased focus on collaborative learning that would challenge traditional, lecturebased instruction.

Health professions education has long met the challenge of simultaneously providing competency-based training and knowledge acquisition through curricula characterized by significant amounts of experiential learning, including laboratory exercises, simulations, and clinical rotations. These programs are costly in terms of faculty, equipment, and facilities, so the institutions' capital investment and the tuition burden on students can be significant. Despite the growing number of entry-level health professional programs in the United States, institutions of higher education face the challenge of educating a sufficient number of healthcare practitioners to serve an expanding population of insured individuals, many of whom have complex health issues (AAMC, 2006; Brennan \& Sullivan-Marx, 2012; Mahony \& Jones, 2013). In addition, the demographics of the United States are regarded as "greying," reflecting the projected growth in the oldest segment of the population from $12.9 \%$ in 2009 to $19 \%$ by 2030 (Administration for Community Living, 2012). In response, the Association of American Medical Colleges (AAMC) and other agencies have called for expanding the number of health professionals to be trained (2006). Simultaneously, there is a call to redesign the delivery of health professions education to incorporate more active-learning strategies, such as problem- and case-based learning, and more individual reflection for prompting critical thinking, all of which promote higher level learning skills (Prober \& Heath, 2012). Given these demands, instructors face the challenge of designing course curricula that will reach beyond learner familiarization with content to application in real-world settings, while negotiating increased class size and expanded curricula, without sacrificing the "hands-on" experience required to build competencies required of future healthcare practitioners.

Increasing numbers of healthcare education programs are adopting web-based and blended approaches in response to the need to reduce cost and promote increased flexibility and learner-centered instruction (Cook, Garside, Levinson, Dupras, \& Montori, 2010; Cook, Levinson, Garside, Dupras, Erwin, \& Montori, 2008; Lahti, Hätönen, \& Välimäki, 2013; Ruggeri, Farrington, \& Brayne, 2013). Perhaps these changes reflect the proposition that healthcare reform will require healthcare education that increases digital literacy (Ruggeri et al., 2013), adoption of educational technology, and faculty development, which focuses on innovation in teaching and learning (Thibault, 2013). Ruggeri et al. argue that successful adoption of online learning programs in healthcare education requires appropriate institutional characteristics (e.g., a supportive culture, information technology support, and organizational 
readiness); instructors with positive attitudes toward online and blended approaches, positive attitudes toward learners, and educational and technological competency; motivated, digitally competent learners with positive attitudes toward online learning; and blended programs that balance face-to-face (FTF) learning with the flexibility allowed by online learning (p. 315). Reasons for "slow" adoption of online education by faculty include a lack of institutional support for both course development and delivery and a perceived loss of contact with students (Kowalczyk, 2014, p. 486).

Blended learning contexts are comprised of both face-to-face class sessions and online learning experiences (Bonk \& Graham, 2006). In this delivery model, didactic materials (readings and lectures) can be placed in the online component of a course, reserving valuable face-to-face time for the application of course content and socialization of concepts among peers and faculty, which are critical to achieving higher levels of learning (Illeris, 2003). Appropriate sequencing and integration of face-to-face class sessions and online discussions can promote a cycle of reflection, application, interaction, and further reflection that encourages self-regulation of learning (McDonald, 2012). As a result, this model of delivery can acculturate health professions students to the type of self-regulated behavior required for competent practice in health professions (Artino et al., 2012).

Yet prior to adopting new models of learning delivery, institutions must address the needs of faculty who will be designing and delivering learning in new — and perhaps initially challenging — ways. Professional development is recognized as critical to successful adoption of blended learning by institutions (Graham, Woodfield, \& Harrison, 2012; McDonald, 2012; Porter, Graham, Spring, \& Welch, 2014). Faculty may need to develop new technical and pedagogical skills appropriate to the blended format (Kowalczyk, 2014; Matzat, 2013; Ocak, 2011; Porter et al., 2014). When facilitating blended courses, "instructors must consider how content delivered in the online component relates to content delivered in the face-to-face class sessions, how to promote interaction between both environments, and how to increase learner awareness of the process of learning in a blended environment in order to ensure success in blended courses” (McDonald, 2012, p. 279). Additionally, faculty will require technical support as they redesign existing courses, seek to manage new online learning environments, and address questions from students adjusting to a new learning model (Porter et al., 2014; Taylor \& Newton, 2013). When considering adoption of blended learning, professional development becomes especially crucial in disciplines heavily reliant upon traditional models of learning delivery, such as health science disciplines. Adoption of different learning models in these disciplines, particularly blended models, may require a paradigm shift for both faculty and students.

Health Sciences at GW is comprised of departments of Clinical Research and Leadership (CRL), Physician Assistant (PA) Studies, and Physical Therapy and Health Care Sciences (PT). CRL is comprised of multiple fully online programs, while PA and PT offer programs mostly in the traditional face-to-face model, with a few courses enhanced through online technology. Future goals for Health Sciences at GW include expansion to a satellite campus and offering additional programs in a blended format. With that end in mind, the Associate Dean of Faculty Development, who has experience in blended learning, is committed to attracting faculty from current programs who are interested in modifying their traditional courses into a blended format. However, prior attempts at online learning in our PA program met with resistance from both students and faculty. Additionally, both the PT and PA programs require experiential, hands-on learning traditionally offered in a face-to-face format, so blending is unfamiliar to both faculty and students. Anecdotal evidence suggests some faculty and students share the perspective that there is a loss of personal contact in online education, which hinders the adoption of technology in fields reliant upon fostering the students' abilities to interact with patients in a compassionate, competent manner.

The ultimate goal in promoting adoption of technology to support learning in health sciences is improved pedagogy aligned with the needs of future healthcare practitioners. Anticipation of potential resistance to the adoption of technology in traditional programs encouraged a progressive approach that allowed faculty to either enhance or blend a course depending on their pedagogical goals. Successful adoption of blended learning can depend on institutional distinction between modes of learning delivery (Garrison \& Vaughan, 2013; Moskal, Dzuiban, \& Hartman, 2013; Porter et al., 2014). Correspondingly, 
the following definitions of technology-enhanced, blended, and online learning were provided as guidelines:

\section{Technology-Enhanced}

Augmenting a traditional face-to-face course with online technology (Allen \& Seaman, 2013) for a specific pedagogical purpose with no reduction in class time

\section{Blended}

Integrating online activities with traditional face-to-face class activities in a planned, pedagogically valuable manner while reducing face-to-face class time (Picciano, 2009)

\section{Online}

An asynchronous course offered fully online with no face-to-face class activities

This article presents two faculty-development initiatives at GW designed to encourage a pedagogical approach to the transformation of traditional face-to-face courses in health science programs to include increased online learning technologies (either to enhance or blend a course). "Branding" the two faculty development initiatives challenged faculty to reconsider the design of their courses and to question how technology might be integrated from a pedagogical perspective (Picciano, 2009). It also allowed them to seek assistance with technological integration. First, the Review, Refresh, and Revise (R3) program (Figure 1) involves an intensive process spanning several semesters for faculty who volunteer and commit to the program. Second, the Supported Media for Administration, Research and Teaching (SMART) Lab is embedded in the departmental offices to provide assistance to faculty as needed. Subsequent sections of this article describe these two initiatives in more detail, providing specific examples of how they promoted technology-enhanced and blended courses in health sciences. Finally, the article details the model used to evaluate course redesign and preliminary research findings.

\section{Our Pedagogical Approach}

Two faculty development initiatives encouraged faculty to reconsider the use of technology in support of learning from a pedagogical perspective. The R3 program (Figure 1) will be discussed first.

\section{Figure 1. Diagram of R3 Process}

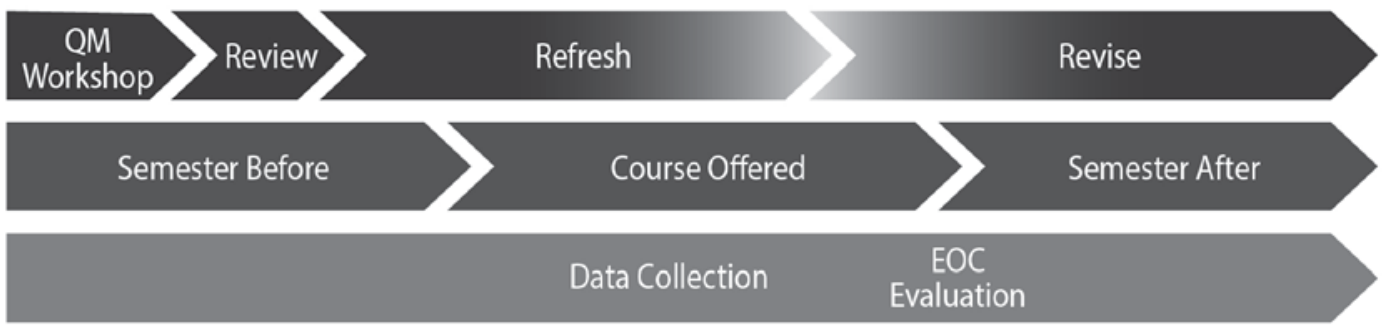

In the R3 program, the Quality Matters (QM) rubric provides an evidence-based approach to course design when working with faculty. The fifth edition of the QM rubric is a set of 43 specific standards used to evaluate the design of online and blended courses that promotes a pedagogical approach to course redesign (Quality Matters, 2014). The rubric is updated every three years and the QM program supplies documentation of the scholarly research that informed the development of the standards. The faculty in our programs appreciate the evidence base supporting the rubric.

The concept of alignment serves as a major part of the QM rubric and the Applying the Quality Matters Rubric workshop completed by faculty at the beginning of R3. QM identifies alignment as 
occurring when each of the critical components of a course (learning objectives, assessment, materials, learner activities, and course technology) work together to ensure that students achieve the desired learning outcomes. When a course is aligned, each of the components directly supports the learning objectives, and anything extraneous to the objectives is avoided. This concept is also known as integrated course design (Fink, 2013, pp. 69-70). For many faculty participants, the idea of alignment in course design was something they had never encountered before, and it became a buzzword among faculty around the office. This result is an unanticipated benefit of adopting the QM approach.

The R3 program is highly collaborative and specific to the needs of each individual faculty member. The faculty instructor, an instructional designer, another faculty member with experience in online and blended learning, and a multimedia specialist work as a team during the process. The process begins at least one semester before a course is offered. Members of the review team use the QM rubric to conduct an individual, informal "Review" of the course (the first step of the R3 process). The rubric is applied informally in that the team does not conduct official peer reviews through the QM program but still goes through the same process in that all three team members use each standard to review the course and make recommendations for course improvement. The team members then compare findings and suggestions and develop an agreed upon approach to "Refresh" the course (the second phase of the R3 process). The outcome of this meeting or meetings is a to-do list of who will do what to refresh the course.

In the "Refresh" phase, faculty must feel supported to complete course redesign. The amount of assistance required by faculty varies by individual. Some faculty require very little assistance following the course review. Others require much more support in terms of developing assignments and activities, working in Blackboard courses, and developing new media for the course. Much of this assistance is help with using technologies that some instructors have not used before to better meet course objectives.

Unsurprisingly, the "Refresh" phase usually continues into the semester when the course is being offered. R3 faculty and staff provide the faculty instructor with further assistance as needed while the course is offered. The "Revise" phase occurs during the semester following the course offering, and includes assessing metrics for the refreshed course and making any further revisions needed. Course metrics include evaluating and incorporating any information collected from sources such as extended end-of-course evaluations, mid-semester student surveys, faculty notes and experiences, and focus groups.

The SMART lab serves as an essential complement to the R3 process and as a resource for all faculty. The lab provides various types of assistance, including hardware, software, and "peopleware" (or assistance with instructional design and technology and media integration). It contains both Apple OSX and Windows workstations with specialized software, and multimedia equipment is available to be borrowed. Additionally, instructional designers and a media specialist provide one-on-one training and assistance as required by faculty.

An important part of these outreach efforts with faculty is to emphasize how technology can be used to promote learning objectives. The pedagogical objective should direct which technological tool should be used, whether it is an on-screen recording, an interactive learning module, or a discussion board in Blackboard. Interaction with faculty never starts with the introduction of the cool new tool. Instead, it aims to align the tool with the faculty's goal for student learning.

\section{Evaluation and Preliminary Data}

The quality of the faculty development initiatives was assessed from various perspectives, including an evaluation of faculty satisfaction, student satisfaction, student engagement, and student learning. The GW Institutional Review Board (IRB) approved a protocol that allows a query of faculty and students about their level of satisfaction with course changes resulting from R3 and SMART lab assistance and to assess their perceptions of the impact of those changes on student engagement and student learning. Faculty who participate in R3 are asked to complete an online faculty satisfaction survey (Appendix A) to assess their satisfaction with the R3 process and their perceptions of the impact course 
changes have had on student engagement and student learning. Additionally, questions are added to an online end-of-course survey students currently take to assess their level of satisfaction with changes resulting from the R3 process and their perception of their level of engagement and learning in relation to specific changes. Appendix B provides examples of questions added to one end-of-course survey. The protocol also allows a review of submitted assignments for evidence of impact on student engagement and student learning. Faculty who receive assistance from the SMART lab are also invited to participate in an anonymous online survey regarding their satisfaction with the assistance they received and its potential impact on student engagement and student learning (Appendix C). Finally, focus groups with both faculty and students can be conducted to interpret data received from surveys and from analysis of student assignments.

\section{Faculty Satisfaction with R3}

Eight faculty completed the R3 program (a group that includes both faculty who teach online and those who teach in the FTF format), and three faculty are currently progressing through the program. Five of the eight faculty (63\%) who completed the program responded to an online satisfaction survey. Faculty who completed the survey agreed that the R3 process improved the alignment in their course, with three of the five strongly agreeing with the improved alignment. Additionally, all faculty agreed that student use of media indicated mastery of course objectives, with four of the five strongly agreeing. When asked to comment on the most effective course changes resulting from the R3 process, one of the faculty commented, "Recognizing which objectives were not being fully addressed and brainstorming creative ways with my reviewers to change some already existing activities and assignments to better address those objectives.” Another noted, "All of the changes to date in my course have been effective."

In addition, two of the eight faculty responded to a follow-on survey regarding the sustained influence of the R3 program on the revised course and on their other courses. Appendix A presents the three questions posed on the follow-on survey. Both respondents agreed that the program helped improve the quality of other courses they teach. One of the faculty noted that "the R3 program provides a great impact to the successful design and revision of an online course. The greatest impact is that it not only fosters the revision of an existing course, but it teaches educators the standards needed to properly align a course so that participants can use these skills as they develop new courses and revise existing courses." The other faculty said, "I feel more attuned to the alignment issues, Blackboard strategies, and assessments."

Five faculty participated in a focus group regarding the R3 process and identified both benefits and challenges. They agreed that one of the greatest benefits was learning about the concept of alignment in course design. They appreciated the outside input into their courses they received from the instructional designer and the additional faculty member on the review team. In addition, participants agreed that the process helped make the activities and assignments in their courses clearer to students. They also indicated that the process helped make the assignments more relevant to the field and to the students. The process was said to "raise the bar" on course assignments. Faculty reported that R3 helped them incorporate different ways of learning into their courses. They also agreed that participating in the process helped them improve the quality of their other courses, both in terms of course design concepts and in practical terms, such as setup of the course in the Blackboard learning management system.

The primary challenge identified in the focus group was the amount of time spent on the process. Scheduling meetings for a three-person team to discuss course design lengthened the process. In addition, none of the faculty participants anticipated the amount of time that would be required when the QM course and all of the associated course adjustments were taken into account. The R3 program has struggled with estimating and communicating an accurate time requirement to potential participants, as we have found the process to be unique to each course and faculty member's needs. In addition to the amount of time faculty spent, some faculty struggled to focus on their course design for the upcoming semester while they were concurrently teaching a different course. Many took the approach of working on their course as it was being taught. Other studies have found similar time-related issues when 
implementing blended learning (Benson, Anderson, \& Ooms, 2011; Napier, Dekhane, \& Smith, 2011; Ocak, 2011). Another challenge faculty indicated in the focus group, noted previously by other R3 participants, was that the close attention to the design of one course often raises curricular issues for a whole degree program. These issues can be challenging for an instructor who teaches one course and does not necessarily have input or control over other courses in the degree program. Lastly, faculty focus group participants noted that there was no clear difference in students' end-of-course evaluations when comparing the revised course to previous courses. The lack of differential may be partially due to a ceiling effect; specifically, some of the courses revised in R3 had already received good course evaluations, but the faculty chose to revise those courses nonetheless because they perceived a need.

\section{Faculty Satisfaction with the Smart Lab}

Eighty-two faculty and staff received assistance from the SMART Lab from August 2012 to July 2014, with many receiving assistance on more than one occasion. Of those, 47 (57\%) completed a survey regarding their level of satisfaction with assistance received and impact on their course and student engagement. Of the 47, only 39 respondents received assistance with a course, so only 39 answered course-related questions. Most respondents (98\%) reported receiving high-quality information and assistance from the lab, and most reported receiving assistance that improved a course or project (98\%). Of the 39 that responded to course-related questions, 97\% indicated that the lab helped them implement tools or technology that increased student engagement in their course. In addition, $97 \%$ indicated that the lab helped them implement tools or technology that increased student learning in their course.

\section{Student Satisfaction with Online or Enhanced Course Changes}

Across four semesters, 330 students completed end-of-course evaluations in courses revised through the R3 process; the response rate was 71\%. Figures $2-5$ indicate student perceptions of course quality, level of engagement, and alignment in these courses.

Figure 2. Course Quality in Relation to Use of Technology

The quality of this course was improved by the use of technology.

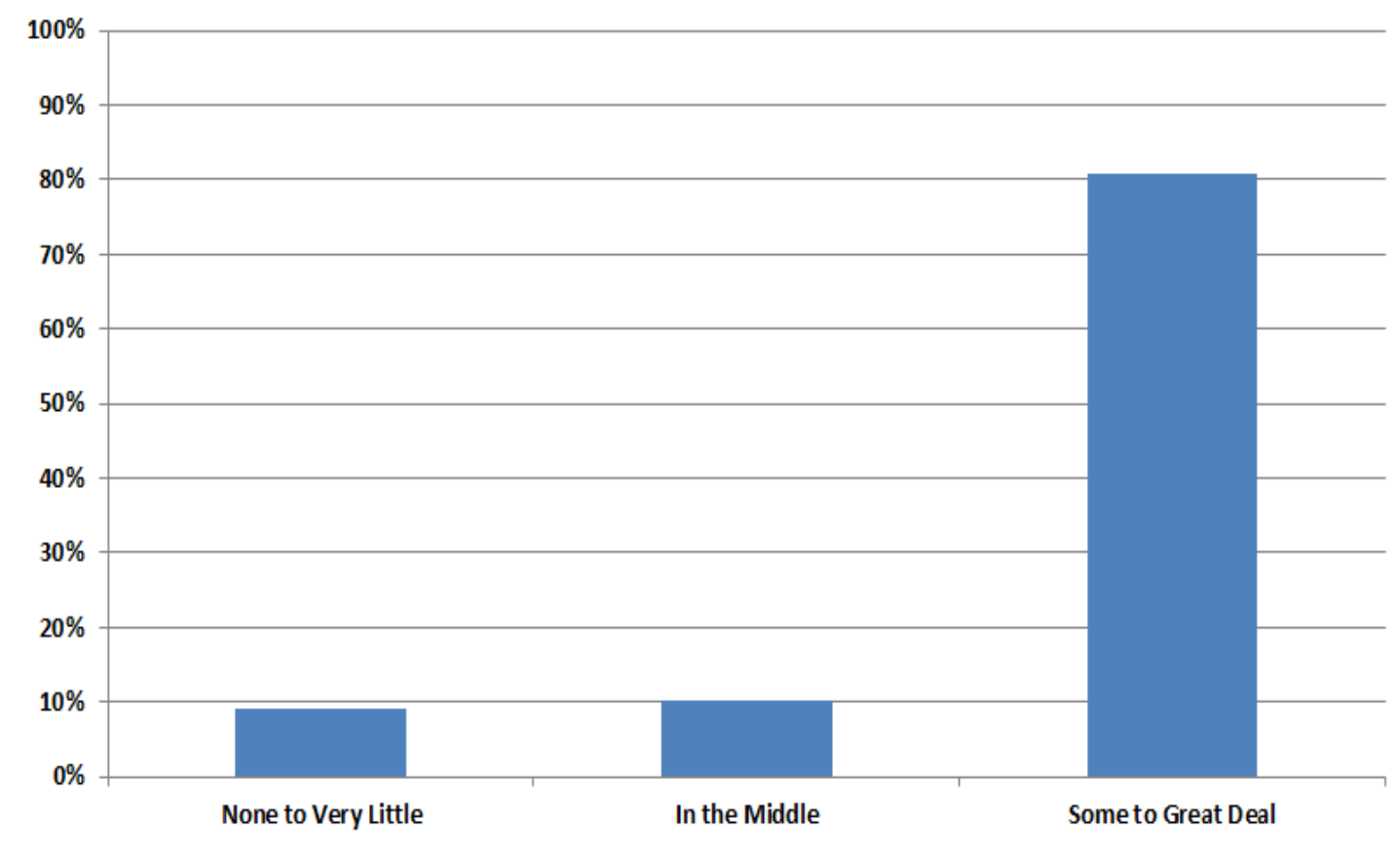


Figure 3. Use of Technology in Relation to Engagement

The use of technology in general helped increase my level of engagement with this course.

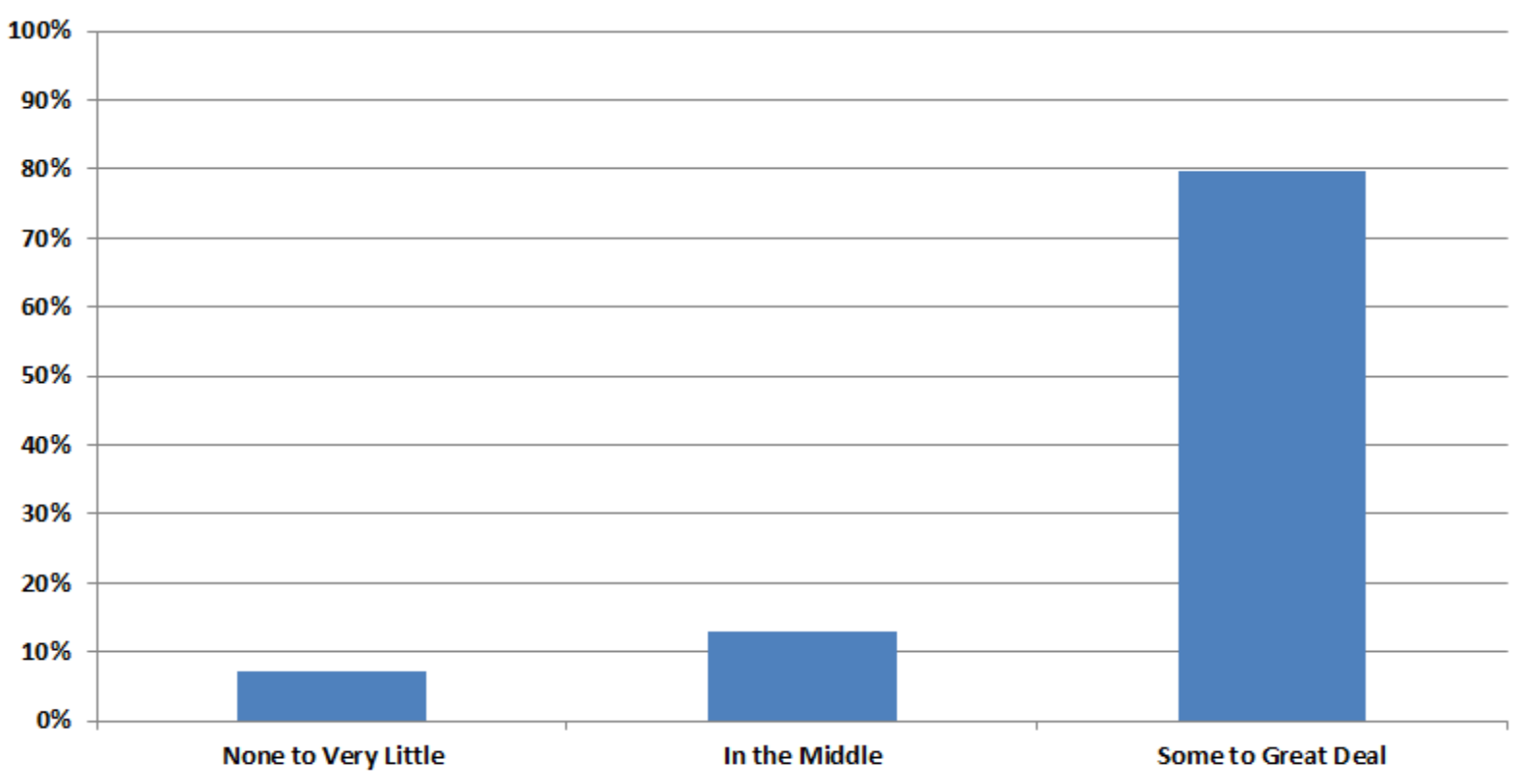

Figure 4. Student Perceptions of Learning from Weekly Online Discussions

The weekly discussion questions helped me learn the course content.

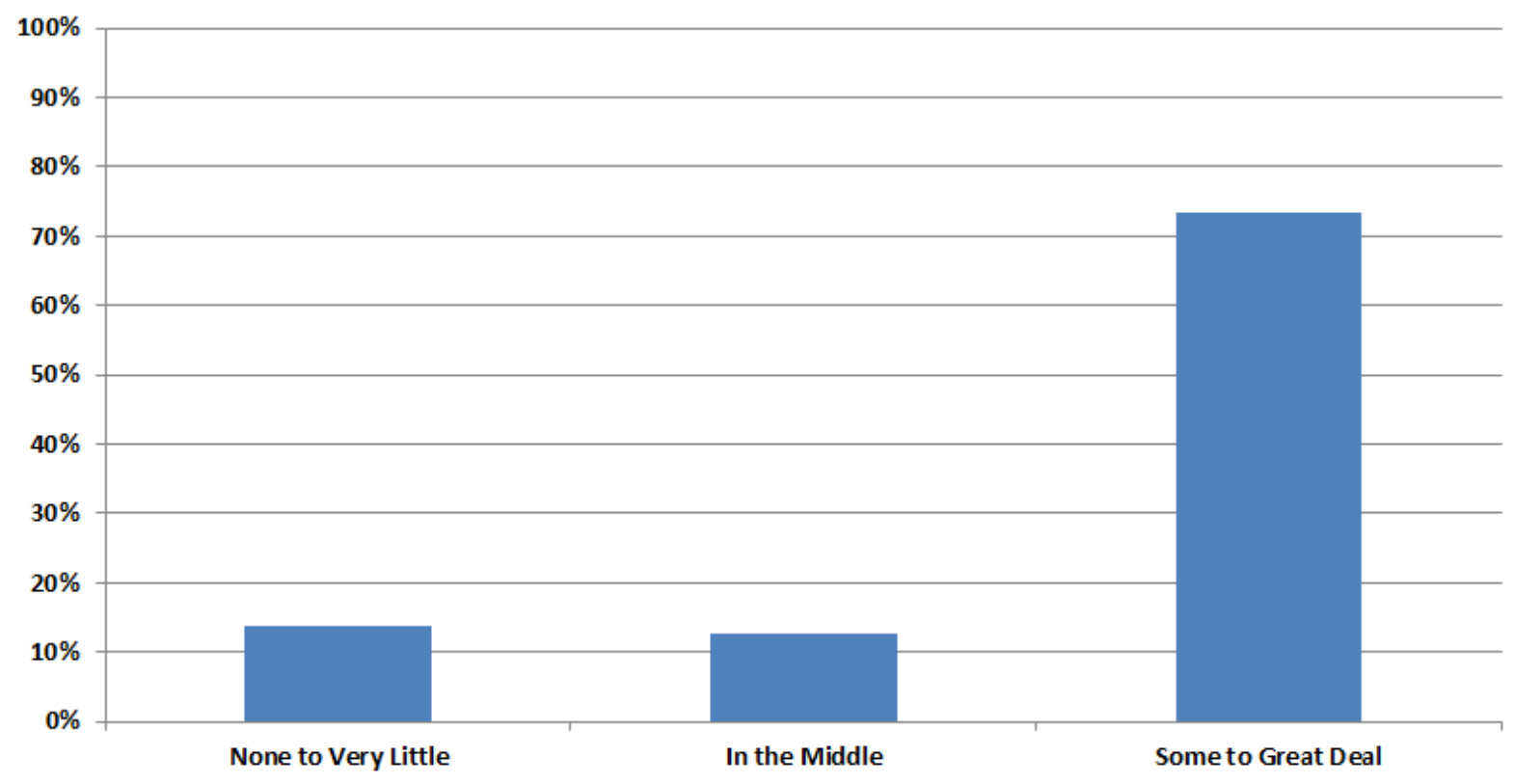


Figure 5. Student Perceptions of Learning from Course Assignments

The graded assignments helped me learn the course content.

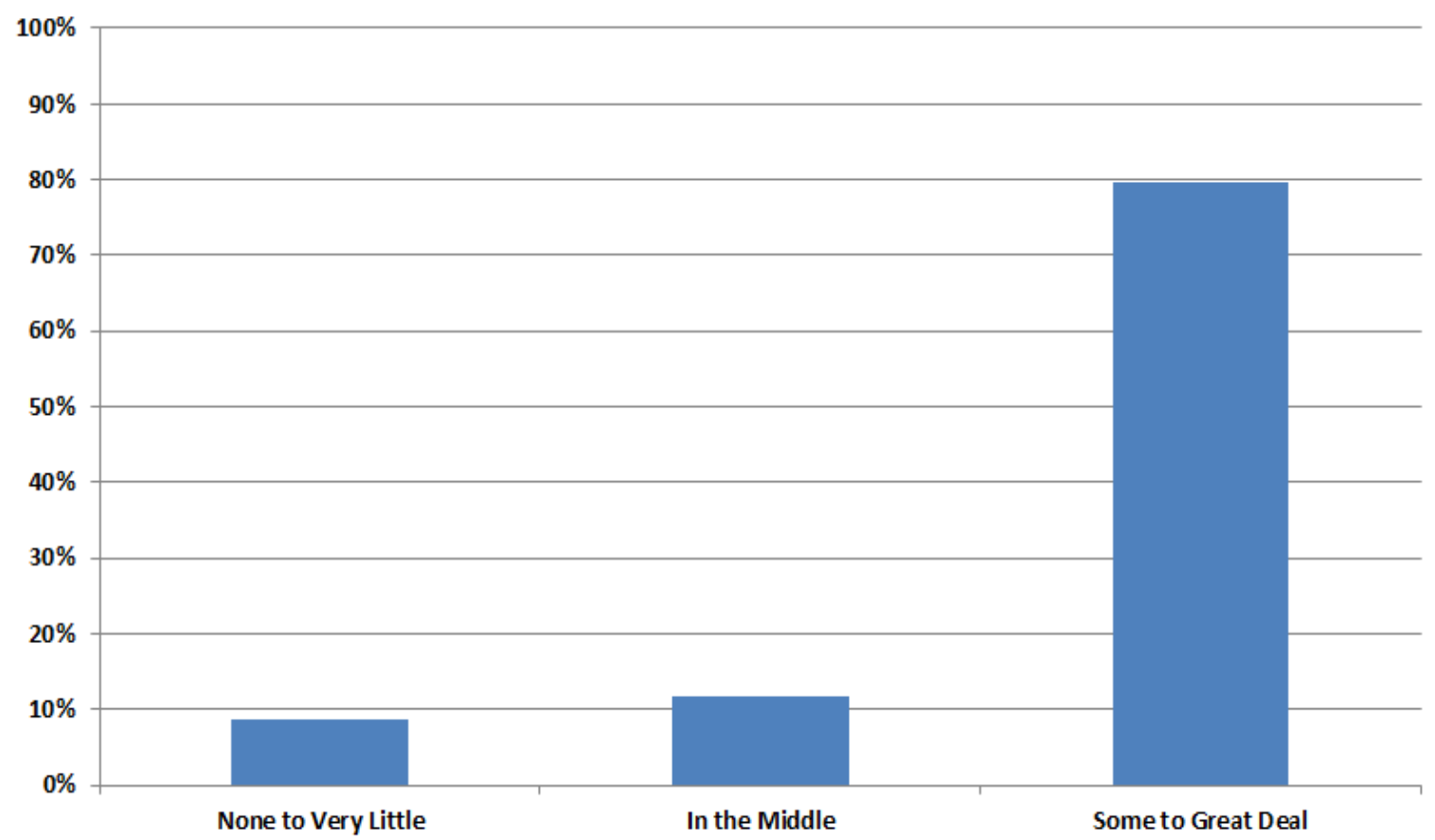

Overall student end-of-course surveys indicated a great deal of satisfaction with R3-related course revisions in fully online and technology-enhanced courses. Survey responses also suggest R3 influences alignment of course assignments with course goals and greater understanding of course concepts, which is a hallmark of the QM process.

\section{Student Satisfaction with Blended Course Structure}

The first fully blended course in the PA program was less well received from a student perspective than changes implemented in online or enhanced courses. Because this was the only course in the program offered in a blended format, we created a separate survey to assess student responses to changes resulting from R3 as well as satisfaction with the blended structure. Forty-three of the 66 students in the course completed the survey (a 65\% response rate). Sixty-five percent of respondents agreed that graded assignments allowed them to apply course content (i.e., course alignment). Also, 67\% agreed that face-to-face sessions reinforced concepts learned online, and $67 \%$ agreed that the online components prepared them for face-to-face sessions. However, responses indicated less appreciation for use of technology in the process of learning. For example, in response to "student-narrated presentation assignments helped me learn course content," only 51\% agreed. Also, responses regarding the degree to which various types of assignments (i.e., the wiki assignment, student-narrated presentations, instructornarrated presentations, online peer discussions, in-class discussion, online quizzes, guest lectures, and online journaling) influenced level of engagement with the course, revealed a preference for in-class discussions (80\% indicating usefulness in promoting engagement) and guest lectures (90\% indicating usefulness in promoting engagement). In comparison, $45 \%$ indicated that online peer discussions were useful in promoting engagement, and 43\% indicated that online journaling was useful. Responses indicated the least engagement with the wiki assignment (32\%).

These results suggest that many students in the blended courses did not perceive the use of asynchronous technology as engaging or as essential to learning course content. The differences in reactions of students in this course as compared to technology-enhanced courses in health sciences 
present a challenge to blended courses in the future for this program. In order to better understand student responses to the blended course, a focus group was held with 12 PA students from a class of 66. The blended course incorporated online discussion questions with the goal of increasing the level of interaction among all students, as instructors wanted to give all students the chance to participate in the conversation, not just those who naturally speak up during class discussion. However, some students indicated that they thought the online discussion questions were busywork and that the discussions felt forced. Additionally, because they all knew each other in person, some students said they did not feel any safer voicing their thoughts in the online discussion as compared to face-to-face in the classroom. The students who did not value the online discussions felt that since they would be interacting with patients face-to-face in their careers, it would be more beneficial to have in-person discussions. Some also felt that sensitive topics, such as those covered in this course, are better dealt with in-person.

Students indicated that the amount of time they spent on the online portions of the course was excessive, although when surveyed as to the amount of time they spent per week on the course, it was appropriate for the number of credit hours, according to Carnegie unit (Shedd, 2003). Despite thinking the online time was redundant and excessive, students in the focus group acknowledged that some students preferred the online discussions and contributed more in that setting. The focus group suggested that the online and face-to-face portions of the course should alternate weeks, although this would mean additional online time, as the blended course was not a 50/50 blend of online and face-to-face instruction. Alternating weeks between online and face-to-face is being implemented during the second iteration of the blended course. A meta-analysis of studies regarding student experiences in online and blended courses by Means, Toyama, Murphy, Bakia, and Jones (2010) concluded that students do spend more time on course-related activities in online and blended courses than in traditional, face-to-face courses. However, the review also suggests "time spent on task" as a potential moderating variable contributing to improved learning outcomes in online and blended modalities as compared to face-to-face delivery (Means et al., pp. 28-29). So while students may feel they are devoting more time to tasks in blended course, the additional time on task allowed by online and blended models may contribute to improved learning outcomes. The challenge, then, is to negotiate the perception of increased workload in online and blended courses as compared to other face-to-face courses while communicating the learning benefits of additional time on task.

It would be too simplistic to say that students are resistant to asynchronous technology in their courses, but students in our focus group highlighted a need to be cautious about the number of technologies in a course and how those technologies are used. Focus group students said that they would have preferred fewer assignment types and they felt that the logistics of the technologies took too much time away from the actual course content. They preferred to "keep it simple.” They also struggled with the timing of the asynchronous multimedia case discussions held in VoiceThread. Because the comments were due just before the next week's lesson, they felt they were not encouraged to go back and engage with their classmates' comments. This time constraint negatively impacted their level of engagement with the VoiceThread activities. They stated that if the discussion were held over several weeks, it would have been more like a conversation. These responses indicate a need for faculty to consider the time it will take for students to learn new technologies in comparison to the learning value of the technology to negotiate students' perceptions of time away from course content. Mediation of time required for learning new technologies may be required to ensure that additional "time spent on task" (Means et al., 2010, p. 28) is devoted to learning and application of content.

Placement of this blended course in the PA curricula may have influenced students' responses to its structure. Students take the course in the first semester of a cohort program, and it is the only course that is blended. So the structure was markedly different than other courses. It may have been difficult for students to adjust to a different learning format while also adjusting to a new program of study. In addition, the course is designed from student-centric perspective and requires active engagement in the learning process on the part of students; yet on numerous occasions students indicated a preference for instructor-centric learning by requesting in-class lectures in which the instructor provided the "right" answers to cases. Students' seeming preference for instructor-centric learning in health science courses is 
one outcome that requires additional research. Further investigation of this topic may support a better understanding of how to overcome potential resistance to adoption of new learning paradigms in programs reliant upon traditional delivery models.

\section{Discussion}

Taken together, the qualitative and quantitative data suggest that a pedagogical approach is effective in encouraging adoption of technology to support learning in health science programs. However, findings also support assertions that adoption of blended learning requires institutional, faculty, and student support (Graham et al., 2012; Kowalczyk, 2014; McDonald, 2012; Porter et al., 2014; Ruggeri et al., 2013; Thibault, 2013). Faculty who received training in how to adopt and revise online learning strategies in relation to pedagogical objectives have responded positively to our initiative and are excited about how technology promotes learner engagement and higher levels of learning, which meets a demand in health professions education (Prober \& Heath, 2012). Additionally, increased familiarity with the concept of alignment caused many faculty to question the design of courses not originally scheduled for R3 revision, in turn raising questions regarding the number of courses we can accept in R3 given current staffing levels and how to prioritize courses in the event of a supply deficit. Consequently, we developed a worksheet of course design and facilitation concerns to help us screen and prioritize courses for participation in R3.

Fortunately, faculty who participated in R3 have become ardent advocates for the concept of alignment and its impact on their approach to course design across their courses. As a result, "alignment" has become quite a buzzword in Health Sciences at GW. For our team, this result indicates that our pedagogical approach, which focuses on teaching faculty skills and concepts rather than "fixing" a course for them, though perhaps more time consuming, has the potential to change faculty's approach to learning design across courses for which they are responsible and, potentially, across all courses and programs we offer. Faculty's echoing of the concept of alignment in relation to the use of technology to support learning, suggests a readiness on the part of our organization to consider new, innovative approaches to achieving pedagogical goals (Ruggeri et al., 2013). Still, through continued success in course redesign and continued support of faculty, we may achieve the cultural change necessary to overcome faculty objections to online and blended learning in health sciences.

However, consideration must be given to addressing the time it takes faculty to redesign and deliver online, blended, and enhanced courses, which serves as a reason for objections to adopting technological innovations in teaching (Benson, Anderson, \& Ooms, 2011; Kowalczyk, 2014; Napier, Dekhane, \& Smith, 2011; Ocak, 2011). Experience indicates that the R3 process takes a great deal of time and individual attention from faculty and instructional designers. Often, the time required for course revision is not known until after the process has begun. For courses that require substantial revision, offering a reduced teaching load for a semester may be necessary to allow sufficient time for revision. Reconsideration of enrollment maximums in a redesigned course may also be required to address the additional time required for course facilitation (Garrison \& Vaughan, 2013).

Achieving the required student support and motivation (Ruggeri et al., 2013) may prove more challenging. While the positive responses of students in online and enhanced course to innovative uses of technology were encouraging, faculty have faced challenges with student responses to blended course design, which has prompted changes to our blended course model. Changes made in response to student feedback offer additional opportunities for us to question how blended courses should be integrated into programs heavily reliant upon face-to-face learning delivery, particularly when the entire program is not prepared to adopt a blended model. These questions relate to properly scaffolding learning activities and the use of technology across courses to allow students to gain familiarity with using technology in the process of learning (Ruggeri et al., 2013). They also relate to adopting technologies most supportive of student mastery of course content while maximizing face-to-face class time for the application and skill development required of future health care practitioners. Student responses might also indicate that they 
require additional time to adjust to a learner-centric model requiring more active participation in the process of learning on the part of the learner. Prior research indicates a need to ensure learner preparedness to engage in blended learning (McDonald, 2012; Tabor, 2007). Perhaps instruction on active learning strategies aligned with blended models might better prepare learners for participation in blended courses.

\section{Future Directions}

Thus far our faculty development initiatives have positively influenced the adoption of technology-enhanced and blended courses across Health Sciences at GW. In fact, we recently created a new online postprofessional Occupational Therapy Doctoral (OTD) program. Additionally, Health Sciences has plans for expansion of its programs to a satellite campus. At this time, it is planned that all new programs offered on that campus adopt a blended format. Given the impending expansion of our programs and the increased interest in enhanced and blended courses in existing programs, we must question the scalability of our current faculty development model and make decisions on additional required resources and prioritization of course redesign.

The perceived resistance of students to blended learning is a perplexing phenomenon that requires additional research. This research suggests that resistance may relate to time, both in relation to perceptions of increased workload (or time spent on learning activities) and to perceptions of increased time required to learn new technologies. As we continue to modify existing blends based upon student feedback, we will also continue to query students regarding their satisfaction with the format and with the alignment of technology usage in achieving learning objectives. For example, students find online discussion redundant when enrolled in a cohort program, which allows multiple opportunities for FTF interaction among peers. So delimiting the use of online discussions in favor of other online technologies may improve satisfaction in blended programs.

In order to continue to promote adoption of technology-enhanced, blended, and online courses across health sciences disciplines, researchers must also continue to question the perceived disciplinary resistance to adoption of technology in learning. Researchers must also seek to discover whether resistance relates to pedagogical concerns (about whether adoption of technology will allow students to achieve similar learning outcomes); to a requisite paradigm shift regarding the process of learning on the part of students and faculty (instructor-centric versus learner-centric); to the increased workloads in blended courses as compared to traditional, face-to-face instruction (Garrison \& Vaughan, 2013); to a reliance upon "tried-and-true" methods of teaching and learning (on the part of faculty and students); or perhaps to a combination of all of these issues. Only when we determine the source of potential resistance can we provide a counterargument favoring adoption of new and innovative ways of teaching and learning with technology. 


\section{References}

Administration for Community Living. (2014). Administration on Aging: Future growth._Retrieved from http://www.aoa.gov/Aging_Statistics/

Advisory Committee on Student Financial Assistance (ACSFA). (2012). Pathways to success: Integrating learning with life and work to increase national college completion. Report to the U.S. Congress and Secretary of Education. Retrieved from http://www2.ed.gov/about/bdscomm/list/acsfa/ptsreport2.pdf

Allen, I. E., \& Seaman J. (2014). Grade change: Tracking online education in the United States, 2013. Babson Survey Research Group, Pearson, and the Sloan Consortium. Retrieved from http://sloanconsortium.org/publications/survey/grade-change-2013

Anderson, J. Q., Boyles, J. L., \& Rainie, L. (2012). The future of higher education. Washington, DC: Pew Research Center's Internet \& American Life Project. Retrieved from http://www.pewinternet.org/2012/07/27/the-future-of-higher-education/

Artino Jr., A. R., Dong, T., DeZee, K. J., Gilliland, W. R., Waechter, D. M., Cruess, D., \& Durning, S. J. (2012). Achievement goal structures and self-regulated learning: Relationships and changes in medical school. Academic Medicine, 87(10), 1375-1381.

Association of American Medical Colleges (2006, June). AAMC statement on the physician workforce. Retrieved from https://www.aamc.org/download/55458/data/workforceposition.pdf

Beckem, J. M., \& Watkins, M. (2012). Bringing life to learning: Immersive experiential learning simulations for online and blended courses. Journal of Asynchronous Learning Networks, 16(5), $61-70$.

Benson, V., Anderson, D., \& Ooms, A. (2011). Educators’ perceptions, attitudes and practices: Blended learning in business and management education. ALT-J: Research in Learning Technology, 19(2), 143-154.

Berrett, D. (2011, September 25). Which core matters more? Differences in definitions of quality lead to new debates over the importance of teaching practical skills versus specific knowledge. The Chronicle of Higher Education. Retrieved from http://www.keene.edu/senate/files/2012/02/Which-Core-Matters-More.pdf

Bonk, C., \& Graham, C. (2006). Handbook of blended learning: Global perspectives and local designs. San Francisco, CA: Pfeiffer Publishing.

Brennan, A. M., \& Sullivan-Marx, E. (2012). The paradigm shift. Nursing Clinics of North America, 47(4), 455-462.

Cook, D., Garside, S., Levinson, A., Dupras, D., \& Montori, V. (2010). What do we mean by web-based learning for health professions education? A systematic review and meta-analysis. Medical Education, 44(8), 765-774.

Cook, D., Levinson, A., Garside, S., Dupras, D. M., Erwin, P. J., \& Mortori, V. (2008). Internet-based learning in health professions: A meta-analysis. Journal of American Medical Association, 30(10), 1181-1196. Retrieved from http://jama.jamanetwork.com/article.aspx?articleid=182536

Fink, L. D. (2013). Creating significant learning experiences: An integrated approach to designing college courses. San Francisco: Jossey-Bass.

Garrison, D., \& Vaughan, N. (2013). Institutional change and leadership associated with blended learning innovation: Two case studies. The Internet and Higher Education, 18, 24-28. 
Graham, C. R., Woodfield, W., \& Harrison, J. B. (2012). A framework for institutional adoption and implementation of blended learning adoption in higher education. The Internet and Higher Education, 18, 4-14.

Illeris, K. (2003). Toward a contemporary and comprehensive theory of learning. International Journal of Lifelong Education, 22(4), 396-406.

Kowalczyk, N. K. (2014). Perceived barriers to online education by radiologic science educators. Radiologic Technology, 85(5), 486-493.

Lahti, M., Hätönen, H., \& Välimäki, M. (2014). Impact of e-learning on nurses' and student nurses knowledge, skills, and satisfaction: A systematic review and meta-analysis. International Journal of Nursing Studies, 51, 136-149. Retrieved from http://www.sciencedirect.com/science/article/pii/S0020748912004592

Mahony, D., \& Jones, E. J. (2013). Social determinants of health in nursing education, research, and health policy. Nursing Science Quarterly, 26(3), 280-284.

Matzat, U. (2013). Do blended virtual learning communities enhance teachers' professional development more than purely virtual ones? A large scale empirical comparison. Computers \& Education, 60(1), 40-51.

McDonald, P. L. (2012). Adult learners and blended learning: A phenomenographic study of variation in adult learners' experiences of blended learning in higher education (Doctoral dissertation). ProQuest Dissertations and Theses, (992950856).

Means, B., Toyama, Y., Murphy, R., Bakia, M., \& Jones, K. (2009). Evaluation of evidence based practices in online learning: A meta-analysis and review of online learning studies. Washington, DC: U.S. Department of Education. Retrieved from U.S. Department of education website: http://www2.ed.gov/rschstat/eval/tech/evidence-based-practices/finalreport.pdf

Moskal, P., Dzuiban, C., \& Hartman, J. (2013). Blended learning: A dangerous idea? The Internet and Higher Education, 18, 15-23.

Napier, N. P., Dekhane, S., \& Smith, S. (2011). Transitioning to blended learning: Understanding student and faculty perceptions. Journal of Asynchronous Learning Networks, 15(1), $20-32$.

Ocak, M. A. (2011). Why are faculty members not teaching blended courses? Insights from faculty members. Computers and Education, 56(3), 689-699.

Oreopoulos, P., \& Petronijevic, U. (2013, Spring). Making college worth it: A review of the returns to higher education. The Future of Children, 23(1). Retrieved from http://futureofchildren.org/futureofchildren/publications/docs/23_01_03.pdf

Picciano, A. G. (2009). Blending with a purpose: The multi-modal model. Journal of Asynchronous Learning Networks, 13(1), 1-9.

Porter, W. W., Graham, C. R., Spring, K. A., \& Welch, K. R. (2014). Blended learning in higher education: Institutional adoption and implementation. Computers \& Education, 7, 185-195. doi:10.1016/j.compedu.2014.02.011

Prober, C. G., \& Heath, C. (2012). Lecture halls without lectures-a proposal for medical education. New England Journal of Medicine, 366(18), 1657-1659. doi:10.1056/NEJMp1202451

Quality Matters (2014). Higher Ed Program>Rubric. Retrieved from https://www.qualitymatters.org/rubric

Ruggeri, K., Farrington, C., \& Brayne, C. (2013). A global model for effective use and evaluation of elearning in health. Telemedicine and e-Health, 19(4), 312-321. doi:10.1089/tmj.2012.0175. 
Shedd, J. (2003, Summer). The history of the student credit hour. New Directions for Higher Education, 122. doi:10.1002/he.106

Staley, D. J., \& Trinkle, D. A. (2011, January/February). The changing landscape of higher education. EDUCAUSE Review, 46(1), 16-33. Retrieved from http://www.educause.edu/ero/article/changing-landscape-higher-education

Tabor, S. (2007). Narrowing the distance: Implementing a hybrid learning model for information security education. The Quarterly Review of Distance Education, 8(1), 47-57.

Taylor, J. A., \& Newton, D. (2013). Beyond blended learning: A case study of institutional change at an Australian regional university. The Internet and Higher Education, 18, 54-60.

Taylor, P., Parker, K., Fry, R., Cohn, D., Wang, W., Velasco, G., . . . Dockterman, D. (2011). Is college worth it? College presidents, public assess value, quality and mission of higher education. Washington, DC: Pew Social and Demographic trends. Retrieved from http://www.pewsocialtrends.org/value-of-college/

Thibault, G. (2013). Reforming health professions education will require culture change and closer ties between classroom and practice. Health Affairs, 33(8), 1928-1932.

Zarate, M. E., \& Burciaga, R. (2010, Fall). Latinos and college access: Trends and future directions. Journal of College Admission. Retrieved from http://files.eric.ed.gov/fulltext/EJ906627.pdf 


\section{Appendix A: R3 Faculty Survey Questions}

Initial Survey Questions

Using a scale of:

- Not Applicable

- Strongly Disagree

- Moderately Disagree

- Undecided

- Moderately Agree

- Strongly Agree

We asked the following questions:

1. The use of the Quality Matters rubric through the R3 program increased the level of alignment between the objectives, assessments, materials, interaction, and technology in my course.

2. The focus on alignment improved the quality of my course.

3. The use of technology in the revised course increased student engagement with the content.

4. Student discussion board postings indicated mastery of the course objectives.

5. Students' formal writing assignments indicated mastery of the course objectives.

6. Students' results on quizzes and tests indicated mastery of the course objectives.

7. Student use of media (student presentations, videos, audio, images, etc.) indicated mastery of course objectives.

8. Please indicate the types of multimedia you used in the course.

- Animations

- Audio files

- Diagrams

- Narrated presentations

- Photos

- Slide presentations

- Tutorials using screen captures and voice over

- Video files

- Other educational media, such as simulations

- None used

9. Please describe the most effective use of multimedia in the course.

10. Please describe the least effective use of multimedia in the course.

11. With regard to changes implemented based on the Quality Matters rubric, please discuss the most effective changes.

12. With regard to changes implemented based on the Quality Matters rubric, please discuss the least effective changes.

13. Please discuss any further changes you plan to make to improve alignment within the course.

14. Please discuss any further changes you plan to make to improve the use of multimedia within the course. 
Faculty Survey Follow-on Questions

Using a scale of:

- Not Applicable

- Strongly Disagree

- Moderately Disagree

- Undecided

- Moderately Agree

- Strongly Agree

We asked the following questions:

1. Since I originally completed the R3 faculty survey, I taught the redesigned course again and feel that participating in the R3 program helped me improve the quality of that course a great deal.

2. Since I first completed this survey, I feel that participating in the R3 program helped me improve the quality of all my courses a great deal.

3. Now that some time has passed, please share any additional thoughts or suggestions you have regarding the efficacy and impact of the R3 program.

\section{Appendix B: Sample of Questions Added to Student End-of-Course Surveys}

Using a scale of:

- Not at all

- $[2]$

- [3]

- $[4]$

- A great deal

We asked the following questions:

1. Course materials helped me learn the course content.

2. The graded assignments helped me learn the course content.

3. In this course, I had the opportunity to assess my own understanding of the course content during the semester.

4. The narrated presentations by the instructor helped me learn the course content.

5. The use of Blackboard helped me learn course content.

6. The use of Blackboard increased my level of engagement in this course.

7. The use of Blackboard improved the quality of this course.

8. Priming activities helped me learn course content.

9. The use of technology in general helped increase my level of engagement with this course.

10. The quality of this course was improved by the use of technology.

11. Please share any thoughts you have regarding the use of technology in this course, particularly as it relates to your engagement with and understanding of course content. 


\section{Appendix C: SMART Lab Survey Questions}

Using a scale of:

- Not at all

- A little

- Somewhat

- A great deal

We asked the following questions:

1. The HSP SMART Lab staff provided me with high-quality information and assistance.

2. The SMART Lab staff provided the amount of assistance and information I needed.

3. I asked the SMART Lab for assistance with a project or question related to: (select all that apply)
a. My course(s)
b. Program administration
c. Program marketing
d. Research project
e. Other

4. The SMART Lab staff helped me get done what I needed to do for my project(s).

5. The SMART Lab provided hardware and/or software that helped me teach my course(s).

6. The assistance I received through the HSP SMART Lab improved the quality of my project(s).

7. The assistance I received through the HSP SMART Lab helped me implement tools and/or activities that increased the level of student engagement in my course(s).

8. The assistance I received through the HSP SMART Lab helped me implement tools and/or activities that increased my students' level of learning.

9. Please discuss the results of the assistance you received through the HSP SMART Lab.

10. Please discuss any suggestions you have for improving the quality of services the SMART Lab provides. 